\title{
Electrochemical erasing using polymer lithography editor for the fabrication of photoactive devices
}

\author{
Nathalie Becerra-Mora, ${ }^{1}$ Annie Y. Vargas-Lizarazo, ${ }^{1}$ Connor Orrison, ${ }^{2}$ Monica \\ Barron $^{3}$, Rajesh P Balaraman, ${ }^{1}$ and Punit Kohli ${ }^{1 *}$ \\ ${ }^{1}$ Department of Chemistry and Biochemistry, Southern Illinois University, \\ Carbondale, IL 62901 \\ 2Old Dominion University, Norfolk, VA, 23529 \\ ${ }^{3}$ Department of Chemistry and Chemical Biology, Indiana University-Purdue \\ University, Indianapolis, Indianapolis, IN 46202 \\ *Corresponding author: pkohli@chem.siu.edu
}

\begin{abstract}
Electrochemical erasing of conductive coatings at microscale for the fabrication of functional devices on flexible and hard surfaces is demonstrated. The nanoporous pyramidal-shaped nano- and micro-scale polyacrylamide hydrogel PLE probes allowed delivery of electrochemical etchants to the surface providing on-demand maskless patterning at microscale. Highly efficient erasing (silver and copper metals erasing efficiency $\approx 100 \%$ ), areal erasing rate $\approx 80 \mu \mathrm{m}^{2} / \mathrm{s}$, and pressure dependent spatial erasing feature dimensions between $3 \mu \mathrm{m}$ to many tens of microns on metal surfaces allowed fabrication of microelectrodes of various geometries. Overall, PLEbased microscale erasing allowed rapid and accessible fabrication of organic
\end{abstract}


electron-hole carrier pair based micro-photodetector, as well as the assembly of LED on flexible and rigid ITO substrates.

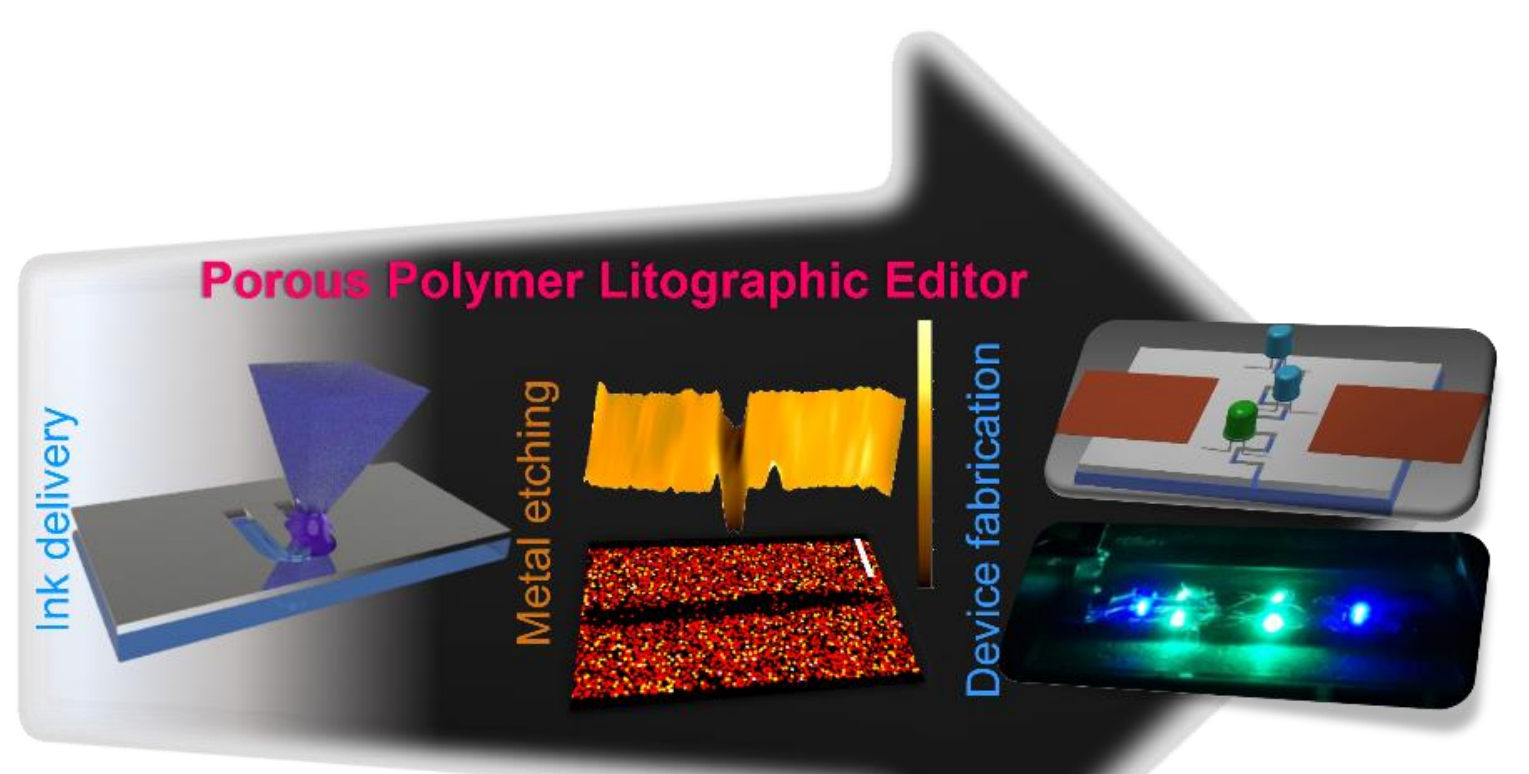

Keywords: Lithographic editor, electrochemical etching, hydrogel, device fabrication, micro-photo-detector

\section{Introduction}

Dip-pen nanolithography (DPN) ${ }^{1-4}$, polymer-pen lithography $(P P L)^{5-7}$, micro-contact printing $(\mu \mathrm{CP})^{8}$, and nano-fountain pen $(\mathrm{NFP})^{9-11}$ have been demonstrated for selective delivery and patterning of a large number of molecules ${ }^{2}$ on a variety of surfaces $^{12}$. A plethora of studies ${ }^{3}$ are published for improving the delivery and the patterning of a large variety of molecules, ${ }^{13,14,15-16}$ the spatial resolution, ${ }^{7}$ and throughput rate ${ }^{17}$. The patterned surfaces and devices fabricated using these techniques possess a wide range of potential applications in bioengineering ${ }^{18}$, 
medical diagnostics, ${ }^{19-20}$ and electronics industry ${ }^{21,22}$, and the number of studies is expected to grow further. ${ }^{23}$

The tip probe-based deposition using DPN, PPL, and NFP are well-suited for achieving ultra-high patterning resolution below $100 \mathrm{~nm}$. DPN is capable of achieving spatial resolution patterning as low as $15 \mathrm{~nm}$ over large areas. ${ }^{24}$ For largescale patterning, a reservoir of molecular ink allows continuous supply of ink. For example, ink reservoirs containing NFP can allow patterning at large scale without a need to redeposit ink in the probes. ${ }^{25}$ For example, use of a cantilever coated with PDMS yielded nanostructures within a range of $60-470 \mathrm{~nm}^{26}$. The reservoirs have also allowed storage of a large amount of ink molecules and particles for deposition. ${ }^{17}$ Additionally, control over the patterning area by changing the pensubstrate contacting area was also demonstrated using soft PDMS probes ${ }^{27}$. Analogously, hydrogel matrixes can be loaded with a large amount of aqueous-ink molecules several orders higher concentration as compared to non-porous probes, ${ }^{28}$ allowing the delivery and deposition of molecules over large areas. ${ }^{29,30}$

In general, probe-based erasing and patterning requires formation a meniscus between the probe and the substrate. This is usually achieved when the probe is brought near a desire surface resulting in the transfer of molecules from the probe to the surface. In the case of PPL, transfer of ink can occur through the meniscus at substrate-probe interface, and through direct contact between tip and substrate as well. This molecule transport mechanism is comparable to the deposition mechanism involved in $\mu \mathrm{CP}$. The rate of molecular transport from probe to the substrate is dependent on the physical and chemical characteristics of the ink ${ }^{31}$, 
substrate, tip material properties, ${ }^{32}$ and environmental conditions such as temperature and relative humidity. ${ }^{33}$ Ink-tip and ink-substrate interactions are key processes that also affect the size of the patterned features in the probe-based patterning. Although the concentration difference based-passive diffusion and/or through fluid dynamics ${ }^{34}$ are dominantly used for molecular transport for the surface patterning, much higher patterning rate ( 2-3 orders of magnitude larger than those observed in the passive transport probe delivery systems) can be accomplished the application of an external electrical potential stimulus between probe and substrate. ${ }^{10,35}$

Although the molecular deposition using probe-based techniques is broadly investigated, the studies describing the selective removal of molecules from surfaces are limited in the literature. For example, nanoshaving, ${ }^{36}$ nanografting, ${ }^{37}$ and electrochemical removal using a conductive atomic force microscope (AFM) tip ${ }^{38}$ are demonstrated for molecular removal and erasing. Because of serial probe movements at nanometer scale during erasing, these techniques can be expensive and time-consuming. ${ }^{39}$ For example, in the case of nanoshaving and nanodrafting, the mechanical erasing requires intimate probe-surface contact that may damage and/or induce defects in probe tips and substrates. Recently, an error rectifying method using polymer lithography editor (PLE) was introduced, where a soft probe composed of agarose hydrogel allowed molecular erasing and writing mediated through a meniscus formed between the probe and substrate. ${ }^{40}$ The rectification process "writing-erasing-rewriting" was demonstrated by "writing" 10 $\mu \mathrm{m}$ fluorescein array dots on glass substrate. The accuracy of erasing was 
demonstrated by placing PLE eraser within $700 \mathrm{~nm}$ of a given registration spot; "rewriting" with fluorescein using PLE at the erased area completed the editing process. The erasing process in PLE involves two major steps: an initial step involves the solvation of the patterned molecules by solvent molecules transported from the tip or molecules that are already present on the substrate surface. This is followed by a second step where solvated molecules diffuse into the nanoporous PLE tip matrix driven by concentration gradient. ${ }^{40}$ Similarly, the writing/rewriting process was accomplished by transport of the ink molecules through the meniscus at the PLE probe-substrate interface. PLE was also utilized for the fabrication of the functional photo-active micro-devices in this study.

Manipulation of physical and chemical properties of the conductive and elastomeric materials has led to the development of flexible electronics devices. These devices possess a wide range of potential applications including, but not limited to, non-linear electronic eyeball cameras, deformable LEDs, 3D micro/nano-structures and functional devices, flexible diagnostic devices for brain surgery, and interfaces for human-computer control systems and related biointegrated devices. ${ }^{41-49}$ The PLEbased lithography is complementary to many lithographic deposition and patterning techniques presently used in industry.

In this manuscript, we show that polyacrylamide (PAAM) hydrogel PLE probes delivered electrochemical etchant molecules selectively to carry out reactions at the microscale level for the functional device fabrication. We demonstrate electrochemical etching of multi-electrode materials (silver, copper, and indium tin oxide) for the fabrication of interdigitated electrodes on soft and hard substrates. 
The interdigitated electrodes were used to fabricate micro-photodetectors using deposition of organic electron-hole pair (P3HT-bis[60]PCBM) on hard substrates. Further, the assembling of LED was accomplished using PLE-assisted microelectrodes fabricated on both hard and flexible substrates. Using PLE, this work demonstrates the fabrication of microscale functional devices in wet laboratory conditions without a need of traditional clean room lithography facilities.

Overall, due to selective spatial etching, PLE allows the fabrication of devices on a variety of substrates including both soft and hard materials and those that may be susceptible to multi-steps harsh conditions employed in traditional photolithography. Importantly, PLE provides mask-less on-demand electrochemical etching at the microscale over large areas in ambient wet conditions. Clean-room conditions are optional for microscale patterning when utilizing PLE. Thus, the main attractive feature of the PLE is that through simple programming of a micro-stage with attached substrate that needs to be patterned allows fabrication of desired patterns at microscale features under ambient conditions. Thus, the use of PLE based fabrication can be potentially useful for fast prototyping without the need of extensive instrumentation and clean room facility.

\section{Experimental section}

A.1 Materials. MCC Primer 80/20 was purchased from Micro Chem. ME 351 (Microdeposit $^{\mathrm{TM}} 351$ Developer) and $\mathrm{S} 1805$ photoresist (Microposit $^{\mathrm{TM}} \mathrm{S} 1805^{\mathrm{TM}}$ Positive photoresist) were obtained from ROHM and HAAS Electronic Materials, Massachusetts. Buffered-HF was purchased from Transene Company, Inc. Danvers, MA. Pyrocathecol (Cathecol $99 \%$ ) was obtained from Alfa Aesar. 
Ethylene diamine 99\% (extra pure), ammonium persulfate 98\% (extra pure), acrylamide $99 \%$, hydrogen peroxide $30 \%$, and sulfuric acid were purchased from Fisher Scientific. Bis-acrylamide was purchased from Amresco, $N, N^{\prime}, N^{\prime}, N^{\prime}-$ tetramethylenediamine $99 \%$ extra pure (TEMED), ferric chloride, and poly(3hexylthiophene-2,5-diyl) P3HT (MW 85,000-100,000) were obtained from Sigma Aldrich. Bis[60]PCBM and potassium permanganate were obtained from $\mathrm{TCl}$ and Mallinckrodt respectively.

A.2. Characterization and methods. The electronic absorption spectrum of bis[60]PCBM and P3HT in o-dichlorobenzene were acquired using a PerkinElmer Lambda 25 spectrometer with a slit width of $1 \mathrm{~nm}$. Emission spectroscopy was performed using a Perkin Elmer LS 55 spectrometer. Both the excitation and emission slit widths were $3.0 \mathrm{~nm}$, and the scanning speed for the acquisition of the spectra was $50 \mathrm{~nm} / \mathrm{min}$. The photo-induced current (PIC) measurements were accomplished using Keithley 6487 picoammeter/voltage source. A xenon arc lamp (300 W) controlled by a power supply (model no. 69907, Newport) provided photoexcitation for photoelectron-induced studies. The optical characterization of the hydrogel pen and electrochemical metal erasing were performed using a bright-field inverted Leica DMIRB microscope.

Scanning Electron Microscopy (SEM) and energy dispersive X-ray spectroscopy (EDS). SEM was performed using a FEI Quanta FEG 450 SEM equipped with an EDX MaxX $50 \mathrm{~mm}^{2}$ Oxford detector controlled using an INCA software. SEM images and EDS were acquired at an accelerating voltage of 10-20kV. Non-conductive 
samples for SEM analysis were coated with a silver or gold-palladium layer (thickness $\sim 100-150 \AA$ ).

Atomic Force Microscopy. The AFM measurements were performed using Autoprobe Thermomicroscopes in contact mode. The microscope was controlled using ThermoMicroscopes ProScan version 1.6 Beta software. The sample was probed with a silicon nitride tip MLCT-AUMT-A with a nominal force constant given by the manufacturer of $30 \mathrm{pN} / \mathrm{nm}$.

\section{B. Fabrication of PAAM PLE probes.}

B.1 Pyramidal silicon master fabrication using photolithography. The fabrication of array pyramidal pores was accomplished using anisotropic etching of $\mathrm{Si}(100)$ plane. ${ }^{50}$ To guide future researchers in the fabrication of lithographic patterning, we provide a detailed flow chart and give some tips that may be helpful for the fabrication of multiple pyramidal pores (Scheme 1). In addition, with the aim to help readers, we captured a sequence of images at each key step of the methodology (Fig. S1). A detailed procedure of the mold fabrication (photolithography and Si anisotropic etching) can be found in the supporting information.

B2. Fabrication of hydrogel probes. PAAM hydrogel was chosen because its mechanical properties and porosity can be modulated by monomer (acrylamide) to cross-linker (bis-acrylamide) ratio $\left(R_{M C}\right)$. For example, variation in the $R_{M C}$ can provide PAAM with a wide range of Young's modulus, porosity, and pore size ${ }^{51}$. The porosity of the PAAM hydrogels enables large capacity for hydrophilic material 
that can be stored within the pores, and it also facilitates the transfer of solute and solvent from/to pores to/from bulk solution.

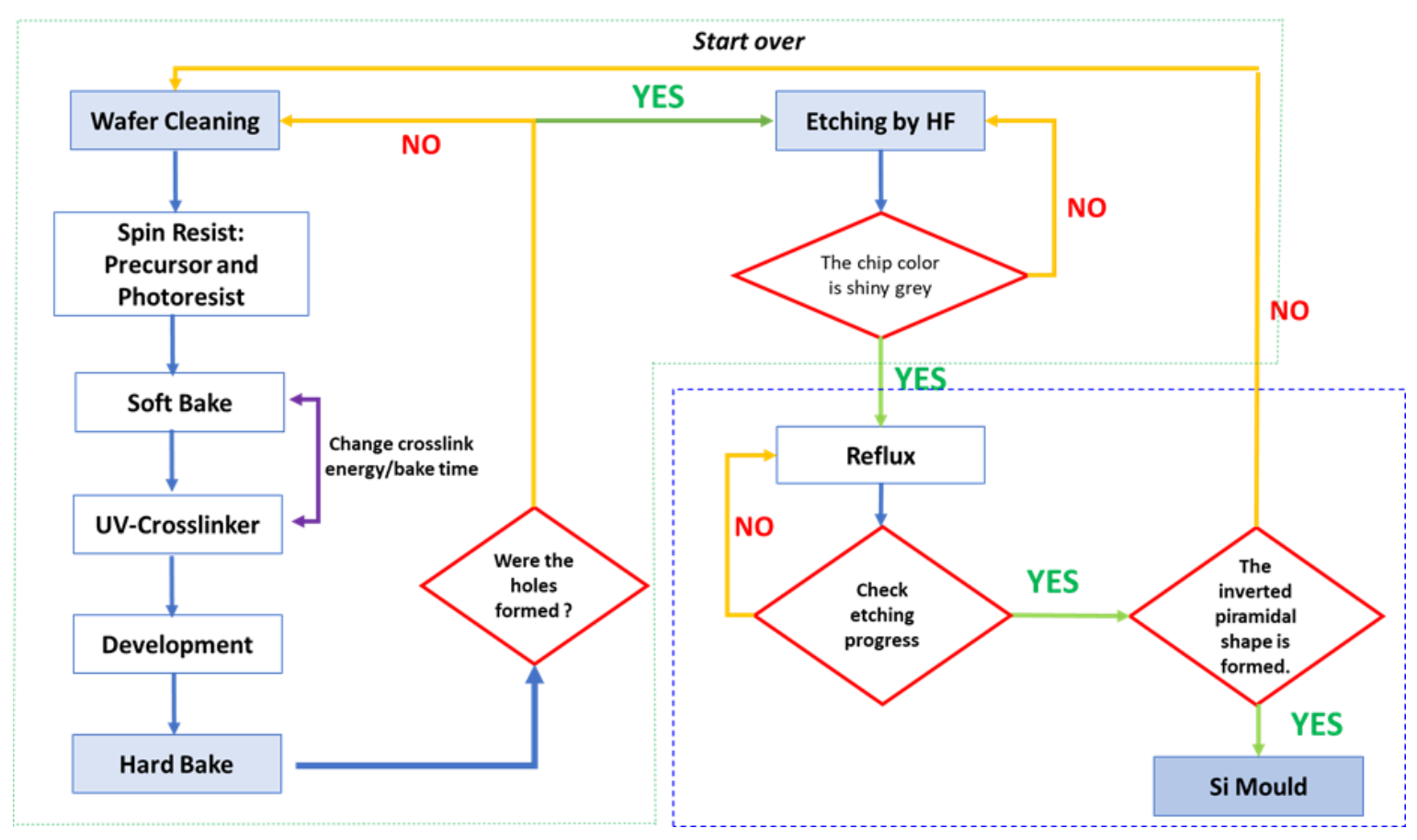

Scheme 1. Flow chart for the Si master fabrication through photolithography and HF anisotropic etching. Fig. S1 shows the optical micrographs of the wafer and the pores at various stages.

Prior to formation of the PAAM PLE probes, the surface of the Si chips was cleaned using $\mathrm{O}_{2}$ plasma for $120 \mathrm{~s}$ (power $250 \mathrm{~W}, \mathrm{Ar} 80 \%, 20 \% \mathrm{O}_{2}$ ). The hydrogel mixture was prepared as follows: $250 \mu \mathrm{L}$ of acrylamide (AM, $100 \% \mathrm{w} / \mathrm{v}), 50 \mu \mathrm{L}$ of bisacrylamide (bAM, $2 \% \mathrm{w} / \mathrm{v}$ ), and $25 \mu \mathrm{L}$ of APS (initiator, $10 \% \mathrm{w} / \mathrm{v}$ ) were vigorously mixed in a $2 \mathrm{~mL}$ tube. This mixture was kept in an ice bath for 2 minutes and $2 \mu \mathrm{L}$ of TEMED (catalyst) was added along the inner walls of the tube. A homogeneous distribution of the components in the solution ensured uniform crosslinking and 
polymerization within the matrix of the hydrogel. $180 \mu \mathrm{L}$ of this solution was added promptly to a Si chip template containing sixteen pyramidal shape pores. The PAAM crosslinking process was rapid and was observed to occur within two minutes of the mixture into the pores. Once PAAM hydrogel was gelled, it was peeled off from the template and stored in nanopure water at $4^{\circ} \mathrm{C}$ until further use. The treatment of the pore templates was not found to be necessary for the release of the polymer probes from the templates.

B.3. Micro-scale electrochemical erasing using PLE-based probes. The microphotodetectors on the PLE probe etched interdigitated electrodes were fabricated by the deposition of an organic electron-hole active pair on the electrodes. Briefly, sputtered $100 \mathrm{~nm}$ thick silver or copper films with a $10 \mathrm{~nm}$ thick $\mathrm{Cr}$ adhesion layer on glass slides was used. The metal substrate was placed on a Leica DMRIB inverted microscope with a Ludl computerized stage that controlled $\mathrm{x}$ - and $\mathrm{y}$-direction movements using an Oasis Blue PCI controller card. The PLE probe was attached to a z-axis piezoelectric stage, and was brought close to the substrate at a vertical speed $\left(v_{z}\right)$ of $0.1 \mu \mathrm{m} / \mathrm{s}$ with a step size of $150 \mathrm{~nm}$. The erasing process was followed on an inverted microscope in transmission mode using microscope objectives (10x and $20 x$ with numerical apertures of 0.25 and 0.40 , respectively). The microscope was equipped with a camera Photometrics CoolSNAP Myo. Briefly, a PAAM PLE containing either $\mathrm{Ag}$ etchant $\left(\mathrm{KI}+\mathrm{I}_{2}\right.$, TFS from Transene Inc.) or Cu etchant ( $\mathrm{Fe}(\mathrm{III})$, CE-200 Transene Inc.) was allowed to make contact with the metal coating using a z-axis piezoelectric stage. For ITO etching, an acidic solution of $\mathrm{Fe}(\mathrm{III})$ containing PAAM single pen attached to the z-piezoelectric stage. The PLE probe formed a 
liquid meniscus between the probe and substrate delivering redox etchants to the substrate that resulted in the erasing (etching) of the metal coating. The relative humidity for all the experiments was $40 \pm 10 \%$. For copper- and silver-coated substrates, the chromium adhesion layer in-between $\mathrm{Cu}$ or $\mathrm{Ag}$ and glass was removed by dipping the substrates in an alkaline potassium permanganate solution. After removal of the chromium etchant, the substrate was rinsed with copious amounts of water and ethanol, then it was followed by air drying. The complete removal of metal coating was confirmed by measuring the electrical resistance of the electrodes. The open circuit was assumed when the electrical resistance of the fabricated electrode was $>1 \mathrm{G} \Omega$.

B.4. Fabrication of micro-photo-detector. An active layer of a light harvesting mixture composed of poly(3-hexylthiophene-2,5-diyl) (P3HT) and bis-phenyl $\mathrm{C}_{60}$ butyric acid methyl ester (bis[60]PCBM) was deposited on the microelectrode. Briefly, $0.02 \mathrm{~g}$ of P3HT dissolved in $2 \mathrm{~mL}$ of $o$-dichlorobenzene was mixed with 0.016 $\mathrm{g}$ of bis[60]PCBM solution in $2 \mathrm{~mL}$ of $o$-dichlorobenzene. $3 \mu \mathrm{L}$ of the active layer was deposited by spin-coating on the electrodes at $500 \mathrm{rpm}$ for 10 seconds (step 1) followed by $1000 \mathrm{rpm}$ for $10 \mathrm{~s}$ (step 2). The spin-coated surfaces were checked for uniformity using optical microscopy. The absorption, emission spectroscopy and atomic force microscopy were used to characterize the active layer of the microphotodetector devices.

B.5. LED assembly on PLE fabricated flexible electrodes. The conductive flexible ITO-PET substrates (Delta Technologies) of dimensions $4 \mathrm{~mm} \times 13 \mathrm{~cm}$ were rinsed with ethanol and air-dried prior to the probe etching for the fabrication of electrodes. 
The film attached to a glass slide was placed on the $x$ - and $y$-motorized stage of the microscope using a double-sided tape (3M). PLE hydrogel probes attached to a piezoelectric stage were soaked in an acidic solution of $\mathrm{Fe}(\mathrm{III})$ for at least one hour prior to the experiment. The PLE was brought in contact to the conductive substrate. The stage was programmed to move with $x$ - and $y$ - speed $\left(v_{x}\right.$ and $\left.v_{y}\right)$ of $5 \mu \mathrm{m} / \mathrm{s}$ in a zig-zig pattern (175 $\mu \mathrm{m}$ in $\mathrm{x}$-direction followed by $200 \mu \mathrm{m}$ in the $\mathrm{y}$-direction) that resulted in inter-digitated electrodes for the fabrication of the microphotodetectors/LED assembly. The metal erasing was performed from edge to edge for an etched length of $\sim 4 \mathrm{~mm}$. The electrical resistance across the inter-digitated electrodes yielded an open circuit system $(>1 G \Omega)$, indicating that the conductive material in the patterned area was completely removed. Blue and green LEDs were glued to the film using silver paint followed by putting a thin layer of super glue for mechanical stability. Copper tape was connected to the two electrodes on the flexible ITO substrates for attaching devices to an external power supply (GW INSTEK GPS-18500). A forward bias of $3.0 \mathrm{~V}$ was used for all LED experiments. Stretching studies on the flexible electrodes was carried out by mounting the LEDITO-PET setup on an $x-y$ stage. The LED glued using silver paint and copper tape on PLE etched devices were then connected to Keithley 6487 (applied potential $\left.\left(V_{a p p l}\right)=3 \mathrm{~V}\right)$. Current and resistance measurements were monitored as the device was stretched with increments of $2 \mathrm{~mm}$.

\section{Results and Discussion}

Pyramidal pores in Si wafers. Fig. 1 shows SEM images of the pyramidal pores obtained using $\mathrm{Si}$ anisotropic etching in an aqueous pyrocathecol-ethylenediamine 
mixture. The activation energy for alkaline etching of $\mathrm{Si}(100)$ planes is smaller than that of $\mathrm{Si}(111)$ planes $^{52}$ that results in higher etching rate for the $\mathrm{Si}(100)$ planes compared to the $\mathrm{Si}(111)$ planes. The size and shape of the pyramidal pore depends upon the shape and size of the exposed silicon during etching. The square-shaped exposed areas on photo-resist coated Si wafers resulted in sharp pointed pores when the etching is proceeded to completion. However, the square-shaped tip

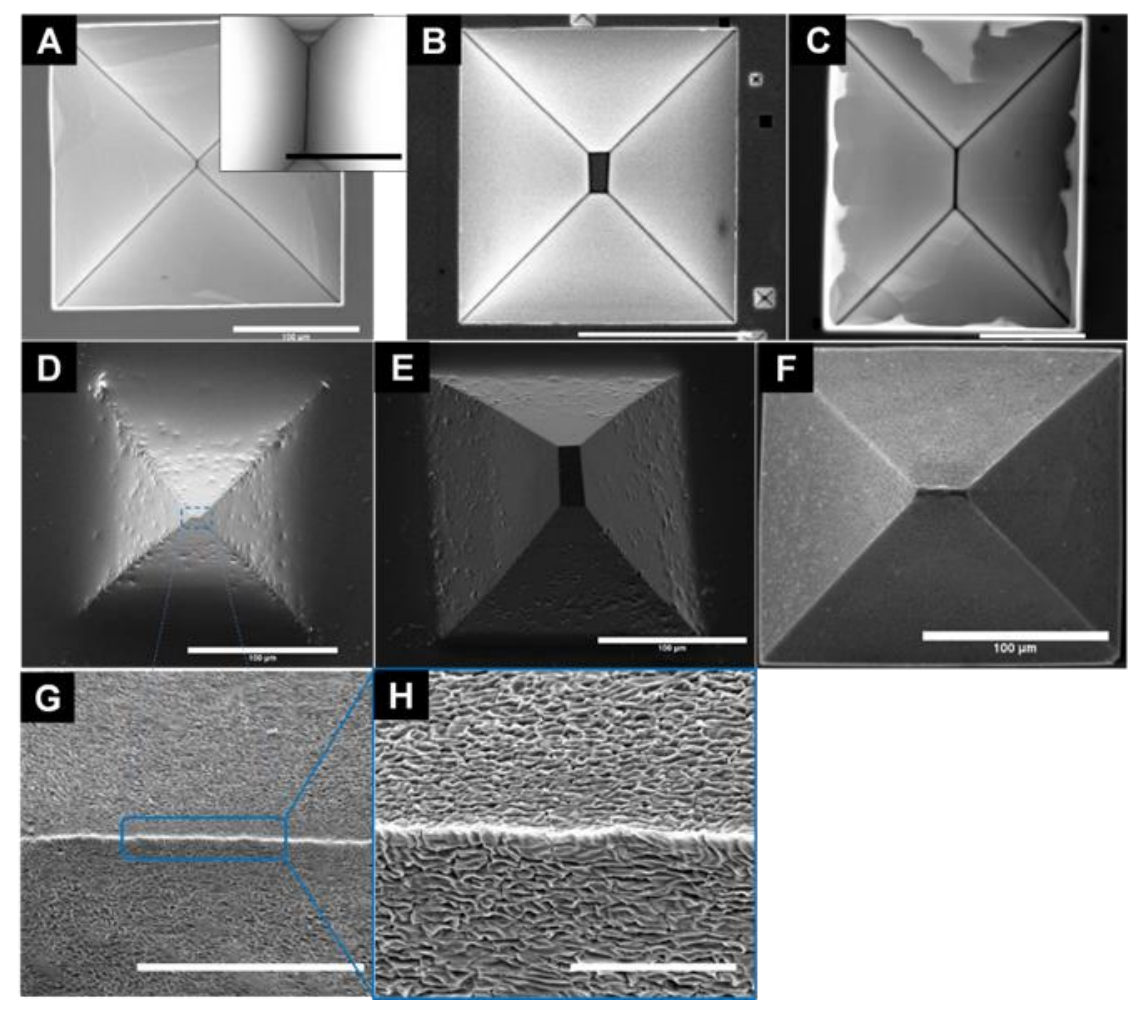

Figure 1. SEM of typical pyramidal pores and PAAM PLE probes. (A) SEM of lineshaped. Inset shows a larger magnification image of the tip, the tip width is roughly $50 \mathrm{~nm}$ (scale bar=4 $\mu \mathrm{m}$ ). (B) and (C) pyramidal pores in Si wafers were fabricated using anisotropic etching of $\mathrm{Si}$ in basic solution. Corresponding nanoporous PAAM PLE probes of line-shaped (D) and rectangular-shaped (E) and (F) were formed by filling the pores up with PAAM solution and peeling them away from the $\mathrm{Si}$ wafer. Higher-resolution SEMs of $(D)$ are shown in $(G)$ and $(H)$ show that the tip is $\sim 300 \mathrm{~nm}$ $x 700 \mathrm{~nm}$ (scale bars are 10 and $5 \mu \mathrm{m}$, respectively). The scale bar is $100 \mu \mathrm{m}$ for images $(A)$ to $(F)$. 
pyramidal pores were resulted when the etching was stopped prior to its completion. Similarly, the rectangular-shaped exposed areas on photo-resist coated Si wafers yielded sharp line or rectangular shaped pores depending upon extend of etching. For example, a line-shaped tip was obtained when the exposed area at the start of the etching is rectangular. However, stopping the etching process at an intermediate stage prior to a complete etching resulted in a rectangular tip pyramidal pore. Fig. 1 shows both the line shaped and rectangular shaped pores in the Si wafer produced in our experiments. The tip $\left(d_{t}\right)$ of the PLE probes ranged between $300 \mathrm{~nm}$ to $64 \mu \mathrm{m}$ depending upon the extent of the $\mathrm{Si}(100)$ etching. Sub-micron PLE line-shaped probe of $300 \mathrm{~nm}$ wide and $700 \mathrm{~nm}$ length was also prepared (Figs. 1D and $1 \mathrm{H}$ ). These sharp tips were used for the fabrication of the PAAM hydrogel probes for the high- resolution erasing applications.

A nanoporous hydrogel PLE probes were prepared by radical polymerization of AM (monomer, M) with bAM (crosslinker, C) in presence of APS (initiator) and catalyst TEMED. The ratio of $C$ to $M\left(R_{M C}\right)$ was $0.2 \%$ in all PLE probes (Eqs. 1 and 2$)$. In practice, both the storage capacity and mechanical properties of the probe needs to be considered for patterning requirements. Therefore, the composition of the PLE probes should be carefully adjusted depending upon the erasing and writing requirements.

$$
\begin{array}{ll}
T(w / v)=\frac{M+C}{V} \times 100 \% & \text { Eq. } 1 \\
C\left(\frac{w}{w}\right)=\frac{C}{M+C} \times 100 \% & \text { Eq. } 2
\end{array}
$$

After crosslinking of the polymer in the pyramidal pores and subsequent peeling off from the Si wafer yielded an optically clear array of polymer probes. Porous PAAM 
probes were imaged using SEM after lyophilization of the hydrogel for a closer visualization at high spatial resolution of the porous matrix (Figs. $1 \mathrm{G}-\mathrm{H}$ ). Although SEM provided nanoscale resolution of the pores, the pore size distribution within the PLE matrix from SEM images cannot accurately obtained. This is because of low contrast limitation for our samples below $10 \mathrm{~nm}$ and a lack of high resolution information deep inside of the PLE matrix. Further, the harsh vacuum conditions used during imaging also affected the pore and interpore dimensions. Finally, a thin conductive metal coating ( 10-15 nm) sputtered for SEM imaging may also damage or distort the sample at nanoscale. Due to these reasons, although the SEM information on the porous PLE is highly useful, the spatial information below $10 \mathrm{~nm}$ however should be interpreted with caution.

Patterning using PLE electrochemical metal erasing. Patterning and deposition of metals to fabricate micro-electronic components at the micro- and nano-scale frequently utilize wet chemical etching of noble metals including $\mathrm{Au}, \mathrm{Ag}$, and $\mathrm{Cu}^{53}$. One reason for their extensive use in electronic and opto-electronic devices is their low electrical resistivity and relatively high chemical inertness to chemical attacks. Metal etching usually involves dissolution of metal using a liquid-phase etchant on selective parts of the metal whereas a masked metal area is protected against the etching. The photoresist masked metal using photolithography followed by isotropic metal etching is shown to achieve spatial resolution as high as $50 \mathrm{~nm}^{54}$.

Device miniaturization in the electronic industry demands development and enhancement in the state-of-the-art of tools and techniques for microfabrication. Several techniques including $\mathrm{FIB}^{55}$ is capable meeting the industry requirements in 
terms of resolution, yet multiplexing, throughput rate of these techniques are not implemented at the industrial scale for device fabrication. Further, in general, appropriate clean room facilities are required for above-mentioned lithography and photolithographic patterning techniques where sub-micron resolution is required. However, the equipment and maintenance costs (including, that of clean room) associated with the above mentioned tools can be extremely high which warrants for alternatives fabrication tools that would help in lowering the cost of device fabrication.

In this report, PLE-based editing is demonstrated for on-demand etching and patterning of metal ( $\mathrm{Cu}, \mathrm{AG}$, and ITO) and other technologically important materials with features at microscale. Further, we also demonstrate here the fabrication of functional micro-photodetectors and LED assembly on soft and hard surfaces that were patterned at microscale using PLE probes.

Electrochemical copper erasing using PLE probes. Fe(III) is industrially used for the etching of the $\mathrm{Cu}$ metal. $\mathrm{Cu}(0) / \mathrm{Fe}(\mathrm{III})$ redox reaction provides water soluble, predominantly $\mathrm{FeCl}_{2}{ }^{+}$and $\mathrm{Cu}(\mathrm{II})$ species. ${ }^{56}$ The overall redox reaction usually represented by Eq. 3 is thermodynamically accessible $\left(E_{o}=0.43 \mathrm{~V}\right)$ :

$$
2 \mathrm{Fe}(\mathrm{III})+\mathrm{Cu}(0) \longrightarrow 2 \mathrm{Fe}(\mathrm{II})+\mathrm{Cu}(\mathrm{II}) \quad \text { Eq. } 3
$$

Importantly, redox reaction $\mathrm{Cu}(0) / \mathrm{Fe}(\mathrm{III})$ is kinetically fast and follows first order rate

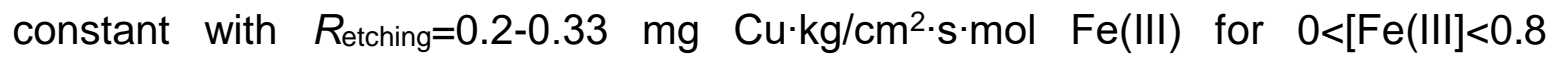
$\mathrm{mol} / \mathrm{kg} \cdot{ }^{57-58}$

Scheme 2 shows the set-up used to perform PLE experiments. The PLE probe was attached to a glass cantilever that was then fixed to a piezoelectric stage (step size 
of $150 \mathrm{~nm})$. By programming the $x-y$ stage as described in the Materials and Experimental section a desired erasing pattern was achieved by delivering etchant molecules contained in the probe matrix to the substrate while moving the stage (Schemes 2B and 2C). Fig. S2 shows the photographs of various parts of set up used in the microscale erasing of various metallic surfaces for the devices fabrication.

Fig. 2 presents a line array patterns of ten electrochemical etched lines fabricated on a $100 \mathrm{~nm}$ copper coated glass, using a rectangular PLE probe impregnated with $\mathrm{Fe}$ (III) (probe tip dimension was $500 \mathrm{~nm} \times 110 \mu \mathrm{m}$ ). Figs. S3 and S4 show EDS color mapping and spectra of PLE probes loaded with $\mathrm{Ag}, \mathrm{Cu}$, and ITO etchants. For line patterns formed in Fig. 2, the $\mathrm{Fe}(\mathrm{III})$ etchant concentration, etching time $\left(\tau_{e}\right)$, relative humidity $(R H)$, and temperature $(T)$ were $3 \%(w / w), 30 s, 40 \pm 10 \%$, and $25^{\circ} \mathrm{C}$, respectively. The width and length of the line shaped patterns were $2.7 \pm 0.7 \mu \mathrm{m}$ and $112 \pm 2.5 \mu \mathrm{m}(\mathrm{n}=9)$, respectively suggesting the microscale features with a narrowetched pattern distribution can be obtained using PLE probes in wet lab settings.

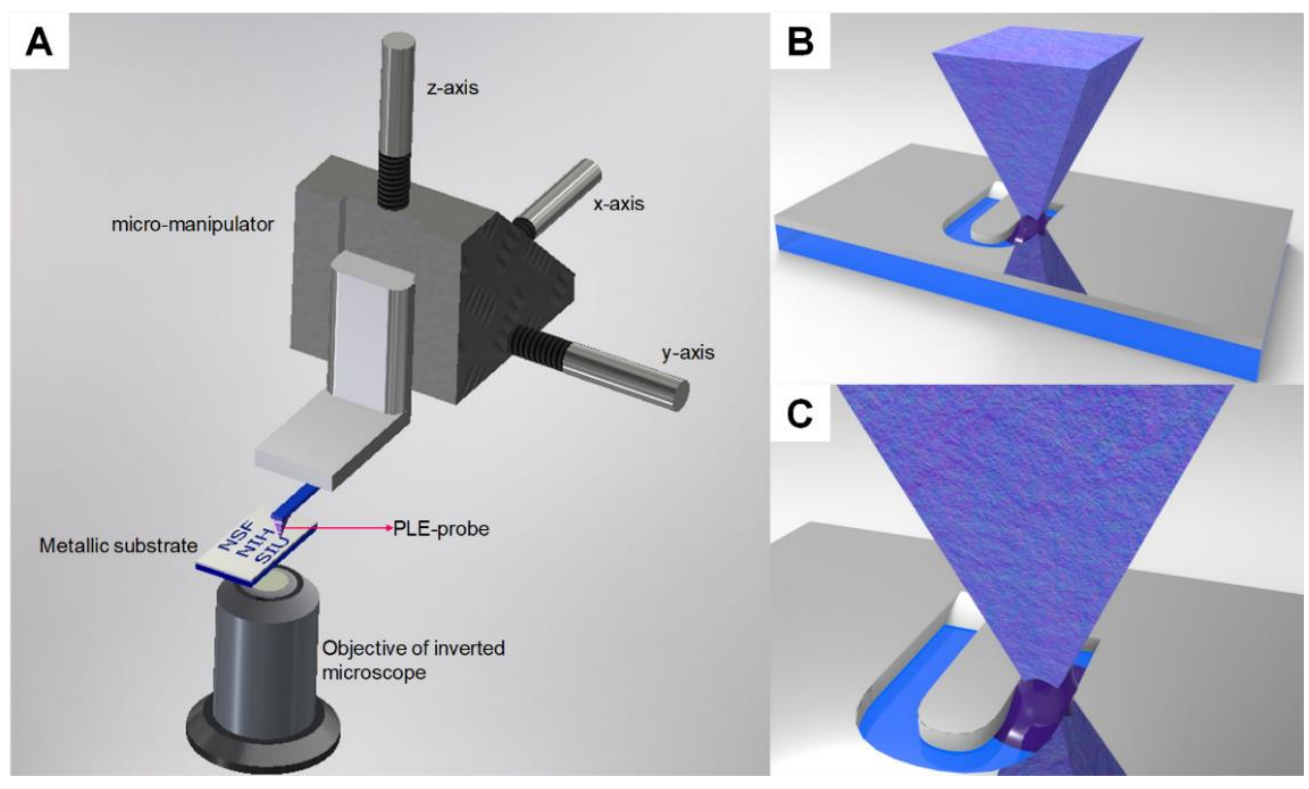


Scheme 2. (A) Schematic of the set-up used for PLE-based erasing. The PLE probe is attached to a glass cantilever which is fixed to a piezoelectric micromanipulator. (B) The relative movement between the substrate and PLE probe loaded with a redox-etchant allowed a desired pattern formation (C) A close up image of the meniscus formed between the PLE probe and the substrate.

It is noticeable that the size of the patterned features is larger than the tip dimension. For example, the patterns formed in these studies were about five times wider ( 2.7 $\mu \mathrm{m})$ than the width of the PLE probe tip of $500 \mathrm{~nm}$ (Fig. 2). This is consistent with our previous studies where the PLE fabricated patterns were also larger than the size of the probe. ${ }^{59}$ The contribution of various factors including meniscus size at tip-substrate interface, molecular interaction between the tip and surface, mechanical properties of the probe tip, and ink-transport characteristics ultimately determine the size of the patterned features. ${ }^{34}$ Further, parameters such as relative humidity, temperature and ink physico-chemical characteristics also contribute to the formation and size of the water meniscus. ${ }^{60}$

In Scheme 2C, the meniscus at the PLE probe-substrate interface is shown for illustrative purposes. However, at this point, we do not know the exact size of the meniscus at the PLE tip-substrate interface. However, we estimate the meniscus at the tip-substrate interface larger than the size of the tip. The erasing process is through a diffusion-based mechanism where the redox etchant from the PLE probe transports etchant to the substrate. ${ }^{59}$ Thus, the PLE erasing is similar to DPN lithography where the solvated ink molecules diffused to the patterning surface through meniscus at the tip-substrate interface. Finally, the erasing pattern size using PLE etching depends upon many experimental parameters, and probe and ink 
characteristics (please see above for more discussion). More detailed studies are needed to fully understand the contributions of each parameter on the erasing pattern dimension.

$\mathrm{Cu}$ etching with PLE probes was also confirmed by EDS and AFM analysis. EDS elemental $\mathrm{Cu}$ and $\mathrm{Si}$ concentration represented by [Cu]EDS and [Si]EDS in the EDS mapping confirmed the depletion of $\mathrm{Cu}$ (Figs. 2B-2E). The orange and purple shaded EDS maps show elemental $\mathrm{Cu}$ and Si respectively (Figs. $2 \mathrm{C}$ and 2D), whereas the elemental $\mathrm{Cu}$ and $\mathrm{Si}$ overlap is shown in Fig. 2E. Under our experimental conditions, the electrochemical $\mathrm{Cu}(0) / \mathrm{Fe}(\mathrm{III})$ redox reaction was dependent upon both the etching time $\left(\tau_{\text {etching}}\right)$ and $\mathrm{Fe}(\mathrm{III})$ concentration. Fig. $2 \mathrm{~F}$ shows that decrease in the $[\mathrm{Cu}]_{\mathrm{EDS}} /[\mathrm{Si}]_{\mathrm{EDS}}$ ratio with $\tau_{\text {etching }}$ for both $[\mathrm{Fe}(\mathrm{III})]=0.3 \%$ and $3 \%$ conditions. $[\mathrm{Cu}]_{\mathrm{EDS}} /[\mathrm{Si}]_{\mathrm{EDS}} \approx 0.1$ suggested that copper was not completely etched but it remained constant for $\tau_{\text {etching }}>45 \mathrm{~s}$ and $[\mathrm{Fe}(\mathrm{III})]=0.3 \%$ (Fig. 2). The etching rate of $\mathrm{Cu}(0)$ was found to increase with $[\mathrm{Fe}(\mathrm{III})]=3 \%$ containing PLE probes - a complete Cu etching was observed for $\tau_{\text {etching }}=60$ s as confirmed using EDS. The quantitative $\mathrm{Cu}(0)$ volumetric etching rate ( $\left.R_{\text {vol,etching }}\right)$ was followed by AFM measurements (Fig. 2G). $R_{v o l, \text { etching }}=\frac{\partial A \times d_{f}}{\partial t}$ was estimated by erased metal area $(\partial A)$ from SEM measurements, known thickness $\left(d_{f}=100 \mathrm{~nm}\right)$ of the coating and erasing time. We estimated $R_{v o l, \text { etching }} \approx 0.5 \mu \mathrm{m}^{3} / \mathrm{s}$ and $1.0 \mu \mathrm{m}^{3} / \mathrm{s}$ with $[\mathrm{Fe}(\mathrm{III})]=0.3 \%$ and $3 \%$ respectively for a rectangular-shaped PLE probes of dimension $500 \mathrm{~nm} \times 110 \mu \mathrm{m}$. 

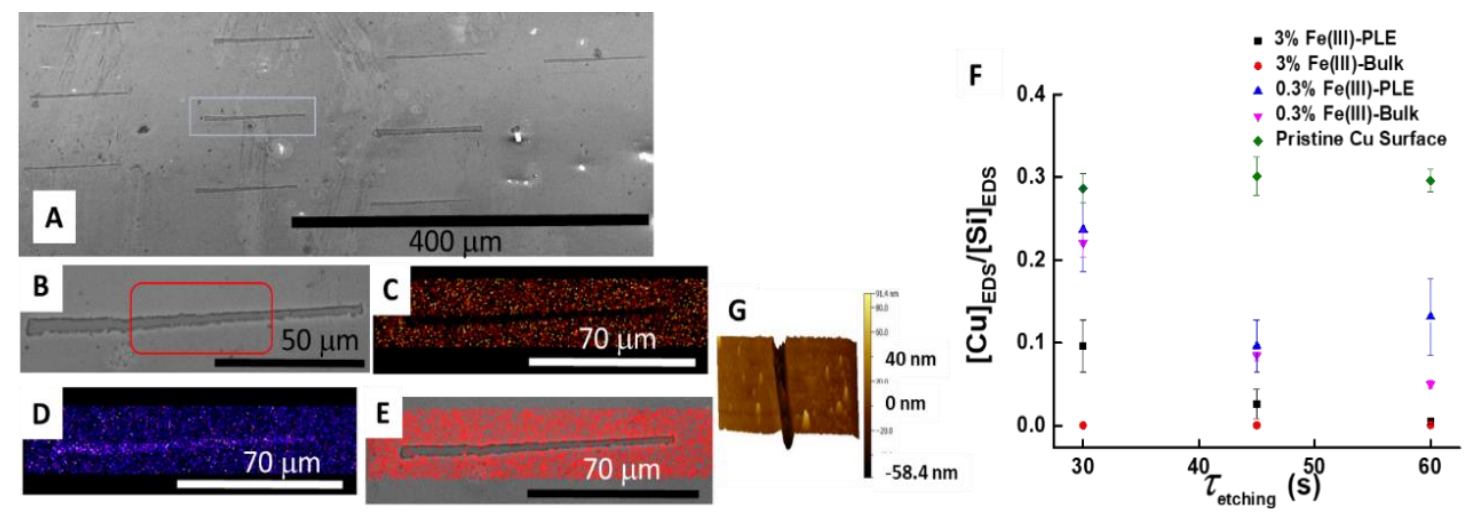

Figure 2. Copper erasing and pattern formation. PLE was used to erase copper and formation of patterns on copper surfaces for the fabrication of the micro-photodetectors. (A) An SEM of an array of rectangular shaped $\mathrm{Cu}$ erased patterns using a PLE probe. The electrochemical erasing was performed using a PLE probe with tip dimension of $500 \mathrm{~nm} \times 110 \mu \mathrm{m} ; \tau_{\mathrm{e}}=30 \mathrm{~s} ; \mathrm{RH}=40 \pm 10 \% ; \mathrm{T}=25^{\circ} \mathrm{C}$; and $[\mathrm{Fe}(\mathrm{III})]=3 \%$. The length and width of the erased patterns were $112 \pm 2.5 \mu \mathrm{m}$ and $2.7 \pm 0.7 \mu \mathrm{m}(\mathrm{n}=9)$ respectively. (B) A higher magnification SEM of an erased pattern in blue rectangle in (A). The EDS mapping analysis shows complete depletion of element $\mathrm{Cu}(\mathrm{C})$ with increase in the Si signal (D). (E) An overlap of elemental $\mathrm{Cu}$ and Si signals. The comparison of the $R_{\text {etching,vor }} \tau_{\text {etching }}$ for the PLE probe and bulk etching is shown in (F). $R_{\text {etching, vol }}$ for the PLE were $0.4 \mu \mathrm{m}^{3} / \mathrm{s}$ and $0.90 \mu \mathrm{m}^{3} / \mathrm{s}$ for $[\mathrm{Fe}(\mathrm{III})]=0.3 \%$ and $3 \%$ respectively, whereas the bulk etching rate was four times larger for $[\mathrm{Fe}(\mathrm{III})]=3 \%$. (G) An AFM of an etched pattern of depth of $\sim 45 \mathrm{~nm}$.

We performed additional experiments to study the etching rates of the copper in bulk conditions and compared this with PLE probe etching. We found that the etching rate was more than four times faster in the bulk solution for $[\mathrm{Fe}(\mathrm{III})]=3 \%$ as compared to the PLE etching $([\mathrm{Fe}(\mathrm{III})]=3 \%$, Fig. $2 \mathrm{~F})$. However, there were insignificant differences in the etching rates between PLE-based and bulk etching for $[\mathrm{Fe}(\mathrm{III})]=0.3 \%$. These results imply that there are differences between the PLEprobe and bulk etching rate depending upon the etchant conditions and that the PLE locomotion speed needs to be adjusted for optimum etching. Although more thorough studies are needed to investigate why this difference would be. One of the possibilities is that at higher etchant conditions beyond a limiting value for the bulk case, the local etchant concentration and mass transport are sufficiently high that 
allowed enhanced etching rate in comparison to the PLE-based etching. Additionally, we also investigated the mechanical stability of the polymer PLE probes. After utilizing the PLE probes for three erasing cycles with $>30,000 \mu \mathrm{m}^{2} \mathrm{Cu}$ erasing, insignificant damage to the probe was evident from the SEM imaging.

The coating thickness employed in the micro-electronics, batteries, and other devices are comparable to those employed here, suggesting that the results in these studies are relevant to the etching of conductive coatings employed in the microelectronics and other related industries. Importantly, we routinely and reproducibly obtained spatial features of $<10 \mu \mathrm{m}$ in width and up to many $\mathrm{cm}$ in length using PLE probes. These results are useful for device fabrication because of the microscale erased feature dimension we can obtain at relatively high throughput rate. With optimization of the PLE probe and etching conditions (etching time, temperature, and etchant concentration), finer etching patterns of sub-micron dimensions with appropriate high throughput rate are feasible.
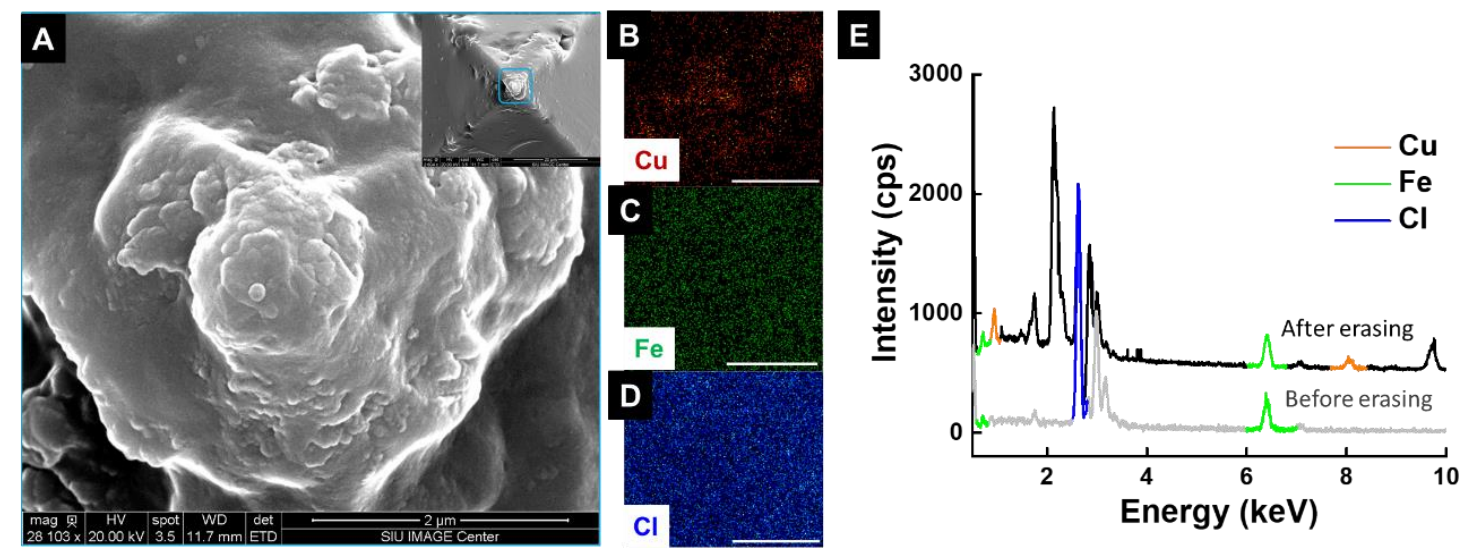

Figure 3. (A) A higher magnification SEM image of a PLE tip loaded with $[\mathrm{Fe}(\mathrm{III})]=0.3 \%$ after $\mathrm{Cu}$ etching (magnification $28 \mathrm{k}$, scale bar $=2 \mu \mathrm{m}$ ). Inset of $(\mathrm{A})$ shows a lower magnification image. EDS color mapping in the PLE probe with $\mathrm{Cu}$ (B, maroon), etchant molecules Fe (C, green), and $\mathrm{Cl}$ (D, blue), scale bars $=2 \mu \mathrm{m}$. (E) The EDS spectrum obtained at the tip of the PLE probe before (bottom) and after (top) Cu etching. Energy peaks at $2.98 \mathrm{keV}(\mathrm{Ag} L \alpha), 2.12 \mathrm{keV}(\mathrm{Au} M), 9.712 \mathrm{keV}$ 
$(\mathrm{Au} L \alpha)$, and $2.828 \mathrm{keV}(\mathrm{Pd} L \alpha)$ came from conductive coating performed on the PLE probe. The presence of Cu $x$-ray peaks in the spectrum suggested the diffusion of the aqueous copper species into the porous PLE probe.

An interesting question arises when metal is removed from the substrate during PLE erasing, what is the fate of the reaction products following the erasing process? In the PLE process, erasing is performed at the probe-substrate interface through an electrochemical reaction between an etchant and metal $(M(0))$. The formation of solvated $\mathrm{M}^{\mathrm{n}+}$ through the redox reaction allows erasing of $\mathrm{M}(0)$. The solvated $\mathrm{M}^{\mathrm{n}+}$ ions diffuse into the probe and to the surrounding areas. In order to address this question, EDS and SEM were used to examine the PLE probe before and after copper etching. A total area of $\sim 28,716 \mu \mathrm{m}^{2}$ was etched using $[\mathrm{Fe}(\mathrm{III})]=0.3 \%$ and $\mathrm{RH}=40 \%$ at $25^{\circ} \mathrm{C}$. Low etchant concentration in the PLE probe and large surface erasing were found to be suitable for investigating the fate of solvated $\mathrm{Cu}(\mathrm{II})$ after the erasing process. Erasing of small areas $\left(<10,000 \mu \mathrm{m}^{2}\right)$ were not successful in the detection of solvated $\mathrm{Cu}(\mathrm{II})$ in the PLE probe, probably due to the EDS detection limit and low concentration of the $\mathrm{Cu}(\mathrm{II})$ into the probe.

The EDS spectra gathered at the tip of the PLE probe showed accumulation of $\mathrm{Cu}$ speciation after etching within the PLE matrix (Fig. 3). Fe Ka and La with energy of $6.398 \mathrm{keV}$ and $0.705 \mathrm{keV}$ respectively, and that of $\mathrm{Cl} \mathrm{Ka} 2.621 \mathrm{keV}$ are shown in Fig. 3E. The energy peaks of 0.93 and $8.04 \mathrm{keV}$ corresponding to $\mathrm{Cu} \mathrm{L} \alpha$ and Ka peaks respectively confirmed the presence of $\mathrm{Cu}$ in the PLE probe (Fig. 3E). It is important to note that the EDS analysis is semi-quantitative in the present studies. Therefore, we cannot over-emphasize the EDS data presented here, although, qualitatively 
EDS results provided a clear evidence of erased $\mathrm{Cu}$ species in the probe. Further, at this point, it is not entirely clear if all the solvated $\mathrm{Cu}$ species diffused into the probe. More extensive quantitative studies are underway to clarify these questions and will be reported in a future manuscript.

The diffusion of the reaction products into PLE matrix can have implication on the erasing process. In the initial stage, the effect of the diffusion of the products into the PLE matrix is expected to be low because the etchant concentration difference (which is the driving force) is large for etchant to diffuse out of the probe. Also, the low product concentration is expected to have an insignificant effect on the erasing rate. However, large area erasing may significantly increase the reaction product concentration in polymer matrix, which, in principle, can hinder the etchant diffusion out of the probe to the meniscus present at the probe-substrate interface. It appears that careful studies are needed to fully understand the effect of diffusion of the reaction products on PLE erasing.

Translocation of PLE probes for metal patterning. Whereas $\mathrm{Cu}$ etching in the previous section was accomplished using PLE probe-copper surface contact, the relative motion between the PLE and the substrate was demonstrated for patterning on $\mathrm{Ag}$ and ITO surfaces. Fig. S5 shows the microscale $\mathrm{Ag}$ erasing patterns accomplished by moving $\left[\mathrm{I}_{2}-\mathrm{KI}\right]=18 \%(\mathrm{w} / \mathrm{v})$ containing PLE probes at a speed of 5 $\mu \mathrm{m} / \mathrm{s}$. A rectangular-shaped PLE probe (dimension $=11 \mu \mathrm{m} \times 24 \mu \mathrm{m}$ ) was used for these experiments. The SEM and EDS measurements of the erased patterns indicated that the complete removal of $\mathrm{Ag}$ from the surface was achieved after two probe passes (cycles) over the pattern. One PLE erasing cycle did not appear to 
etch Ag completely but $\sim 97 \%$ silver remained on the surface after one erasing cycle. The EDS mapping of elemental $\mathrm{Ag}$ and Si confirmed complete erasing after three or more erasing PLE cycles (Fig. S6). Patterns with width and length $\sim 32.2 \pm 11.6 \mu \mathrm{m}$ and $\sim 1330 \mu \mathrm{m}(1.33 \mathrm{~mm})$ respectively, an erased area of $\sim 0.043 \mathrm{~mm}^{2}$ was accomplished which yielded areal speed ( $R_{\text {area,etching }}$ ) and $R_{v o l, \text { etching }}$ of $\approx 80 \mu \mathrm{m}^{2} / \mathrm{s}$ and $8 \mu \mathrm{m}^{3} / \mathrm{s}$ respectively. $R_{\text {area, etching }}=w \times v_{\text {probe }}$ and $R_{v o l, e t c h i n g}=w \times v_{\text {probe }} \times d$; here, $w, d$, and $v_{\text {probe }}$ were width of the pattern, thickness of silver coating, and speed of the probe, respectively. Assuming complete Ag erasing was accomplished in two erasing cycles (Fig. S6) at $v_{\text {probe }}=5 \mu \mathrm{m} / \mathrm{s}$, the observed $\mathrm{Ag} R_{\text {vol,etching }}$ was $\sim 8$ times that of $R_{v o l, e t c h i n g}$ for the Cu where the PLE probe-surface contact mechanism was employed. The $R_{v o l, e t c h i n g}$ depends upon the probe size, concentration and temperature of the redox etchant, and etchant-metal redox kinetics rate. For example, larger probe size delivers larger volume of the etchants that will result in

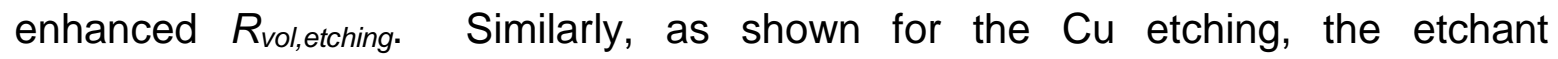
concentration is also an important parameter that affects the etching rate. In our experiments, the area of the PLE probe used for the Ag erasing was $\sim 5$ times larger than the area of the probe used for the Cu etching which may account for enhanced etching rate. Further, the etchant-metal redox kinetics consideration is also important for fully utilization of the probe-based pattern formation. Under optimized conditions, a larger etching rate than those demonstrated here can be obtained by controlling the etchant concentration and temperature, probe dimension, and masstransport and kinetics of the metal-etchant reaction. 
Fabrication of functional micro-photodetector and LED devices using PLE patterned electrodes. The interdigitated electrodes were fabricated by translocating $18 \% \mathrm{w} / \mathrm{v}$ aqueous $\left[\mathrm{KI}-\mathrm{I}_{2}\right]$-complex containing PLE probes over Ag-coated glass wafers at a speed of $5 \mu \mathrm{m} / \mathrm{s}$. Fig. $4 \mathrm{~A}$ shows a schematic of the interdigitated electrode based micro-photodetector fabricated using the PLE erasing. The zig-zag probe movement of the PLE over metallic coating resulted in interdigitated electrodes with conductive metal electrode width and spacing of $50 \mu \mathrm{m}$ and $150 \mu \mathrm{m}$ respectively (inset Fig. 4B). After Ag etching, the electrical resistance of the electrode increased from $<10 \Omega$ to $>1 \mathrm{G} \Omega$ (reliable limiting electrical resistance of our multimeter was $1 \mathrm{G} \Omega$ ) suggesting that the Ag erasing was successful. These results were also confirmed by the EDS measurements (Fig. S6). An electron donor-acceptor pair of P3HT and bis[60]PCBM of $1 \%$ and $0.8 \%$ concentrations respectively were spin-coated on the interdigitated electrodes. The films composed of only P3HT and bis[60]PCBM, and that of P3HTbis[60]PCBM mixture were also characterized using AFM (Figs. S7 and 4C). The emission spectra of $\mathrm{P} 3 \mathrm{HT}$ before and after addition of acceptor in the solution phase indicated an emission quenching efficiency of $\sim 45 \%$ (Fig. S8). These results are consistent with previous studies suggesting strong donor-acceptor interactions, and charge transfer between excited state $\mathrm{P} 3 \mathrm{HT}$ and bis[60]PCBM. ${ }^{61}$ Figure 4B shows the experimental set-up used for the acquisition of photo-induced current (PIC). Fig. 4D shows typical PIC-time responses of a typical micro-photodetector device with light "ON" and "OFF". A solar simulator (AM 1.5) under ambient wet laboratory conditions was used for all photo-induced studies. With photon irradiation, the PIC increases sharply exhibiting both the rise $\left(\tau_{\text {rise }}\right)$ and decay times $\left(\tau_{\text {decay }}\right)<500$ ms. 
The device response was found to stable for less than five "ON-OFF" cycles; the PIC signal response decreased significantly after $>10$ cycles. This decrease in the PIC signal is attributed to photo-degradation of the active organic layer.
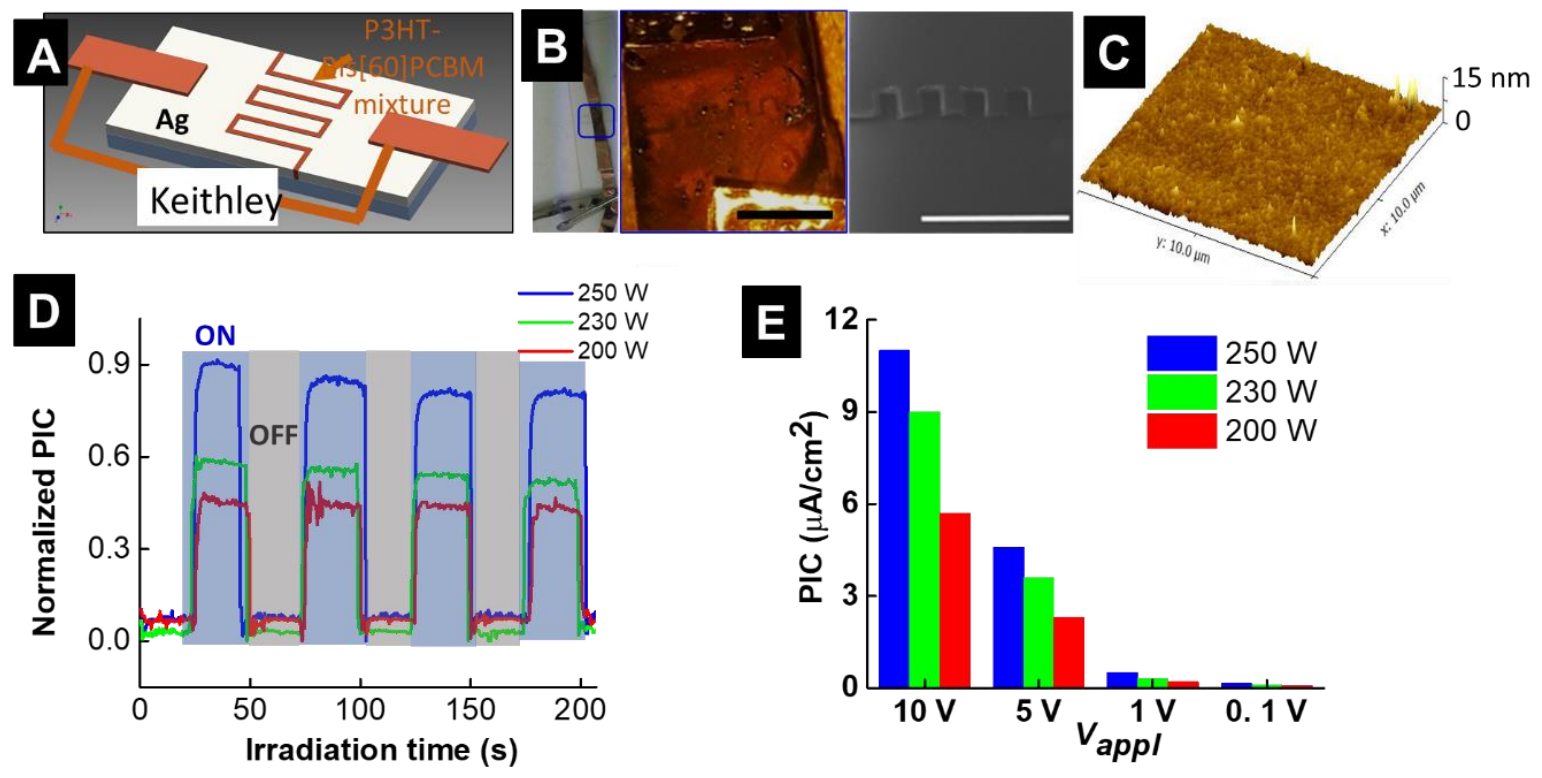

Figure 4. Micro-photodetector fabricated using PLE-based patterning of silver interdigitated electrodes. (A) A schematic of a micro-photodetector prepared by erasing silver in a zig-zag pattern thereby fabricating an interdigitated electrode and spin coating an electron donor-acceptor pair on the electrode (brown zig-zag line). Two copper electrodes were attached to the pattern substrate and connected to electric potential using Keithley 6487. (B) The optical photograph (left) and higher magnification optical photograph (middle) of a micro-photodetector assembly in the blue square. The zig-zag patterns on the electrodes are visible in (B). The darkreddish color comes from the deposition of the donor-acceptor mixture. An SEM image of the patterned electrode (right, scale bar $2 \mathrm{~mm}$ ). (C) An AFM of P3HTbis[60]PCBM mixture deposited on the photodetector. (D) A typical PIC-time response of the micro-photodetector for three different powers (200 W, $230 \mathrm{~W}$, and $250 \mathrm{~W}$ ). The measured photon intensity at $534 \mathrm{~nm}$ (Newport Model: 818-SL) for $200 \mathrm{~W}, 230 \mathrm{~W}$, and $250 \mathrm{~W}$ were $142 \mathrm{~mW} / \mathrm{cm}^{2}, 220 \mathrm{~mW} / \mathrm{cm}^{2}$, and $240 \mathrm{~mW} / \mathrm{cm}^{2}$ respectively. (D) Normalized PIC- $V_{a p p l}$ dependence for the micro-photodetector at three different photon intensities.

Fabrication and testing of devices were performed in wet lab conditions in air $(21 \%$ oxygen and humidity between $\sim 50 \%$ ). Oxygen is singlet in its ground state, and is an excellent quencher for molecules in the excited state. ${ }^{62}$ Both P3HT and PCBM 
are known to oxidize and degrade under photo-irradiation conditions. Specifically, the photo-degradation of $\mathrm{P} 3 \mathrm{HT}$ is a light-initiated radical mechanism where the concentration of the quenched sites increases with the photo-oxidation. ${ }^{63}$ Similarly, PCBM can undergo a series of oxidation when photo-radiated which acts as electron traps as shown by experimental and DFT studies. ${ }^{64}$ The degradation of the performance of the devices such as ours can be minimized by hermetically sealing the devices with materials that eliminate (or significantly reduce) the transport of oxygen, water, and other performance degrading species.

Interestingly, the PIC signal depends on the photo-excitation power $(P)$ and the applied voltage $\left(V_{\text {appl }}\right)$ across two electrodes. PIC-photo-excitation power and PIC$V_{a p p l}$ dependences are shown in Figs. 4D and 4E respectively. In general, higher photon intensity consistently resulted in larger PIC. For example, PIC was 2 times when $P=250 \mathrm{~W}$ than when $\mathrm{P}=200 \mathrm{~W}$. The $\mathrm{PIC}$ enhancement at higher lamp power is attributed to increase in photo-charge generation leading to enhanced PIC. More dramatic PIC- $V_{a p p l}$ dependence was observed under same photon intensity conditions (Fig. 4D). For example, $\mathrm{PIC}_{10,1}=\frac{P I C_{10}}{P I C_{1}}$ was $>20$ for all the photon intensities (200 W, $230 \mathrm{~W}$, and $250 \mathrm{~W}$ ) tested under our experimental conditions. $\mathrm{PIC}_{10,1}$ is a measure of influence of applied potential, and it is defined as ratio PIC at $V_{a p p l}=10 \mathrm{~V}$ to $\mathrm{PIC}$ at $V_{a p p l}=1 \mathrm{~V}$. Similarly, $\mathrm{PIC}_{5,1}$ and $\mathrm{PIC}_{1,0.1}$ were $>9$ and $>2.5$ respectively for our experimental conditions. In fact, $\mathrm{PIC}_{10,0.1>65}$ for all the photon power tested in our experiments. The strong PIC- $V_{a p p /}$ dependence is not surprising for randomly dispersed donors and acceptors in the inhomogeneous film where significant losses due to charge recombination and charge trapping, and other 
charge loss mechanisms exist. ${ }^{65}$ The application of an external electric field drastically decreased the charge recombination and other losses in the device by forcing the electrons and holes to transport to opposite appropriate electrodes, thereby, dramatic enhancing the PIC signal at higher $V_{\text {appl. }}$

LED device assembly on flexible electrodes. ITO coated flexible polyester (PET) substrates $(1 \mathrm{~cm} \times 2.7 \mathrm{~cm})$ were also patterned using PLE probes soaked in acidic $0.2 \mathrm{M} \mathrm{Fe}(\mathrm{III})$. Etching of ITO with acidic $\mathrm{Fe}(\mathrm{III})$ is thermodynamically favorable with a reported activation energy of $56 \pm 5 \mathrm{~kJ} / \mathrm{mol} .{ }^{66}$ The $\mathrm{Fe}(\mathrm{III})$ containing PLE probes were translocated at a speed of $5 \mu \mathrm{m} / \mathrm{s}$ over the ITO surface. Under these experimental conditions, multiple PLE probe erasing cycles were needed to completely etch ITO from the surface. The electrical resistance-number of erasing cycles dependence is shown in Fig. 5A. The electric resistance $(R)$ of the ITO surface increased from $500 \Omega$ to $>50 \mathrm{M} \Omega$ after four erasing passes for an etched line of $\sim 200 \mu \mathrm{m} \times 1 \mathrm{~cm}$ line suggesting successful ITO erasing (Fig. 5A). A schematic and a typical working device with six LEDs (four green and two blue) mounted on the PLE etched ITO substrate are shown in Figs. 5B and 5C, respectively. We examined the working behavior of an LED assembled on a flexible ITO-PET substrate by mounting it on a mechanical station for stretching experiments (Figs. $5 \mathrm{D}, 5 \mathrm{E}$, and S9). Stretching and relaxation of the unstrained state in the first cycle did not result in a significant change in electrical resistance $\left(R_{e x t}\right)$ under strain $(\varepsilon)$ up to $\varepsilon$ up to $4.5 \%$ (two-way black arrows) (Fig. 5F). A second stretching cycle with $\varepsilon=4.5 \%$ (two-way red arrows) led to increase in $R_{e x t}$ by an order of magnitude which however returned to the original value after relaxed to $\varepsilon=3 \%$ showing limited 
electrical reversibility of the PLE fabricated devices on ITO coated polyester substrates. For $\varepsilon=7.6 \%$, however, $R_{\text {ext }}>1 \mathrm{G} \Omega$ was observed. This is due to tearing of the ITO-PET substrates that resulted in the destruction of the conductive pathways for charge transport through the devices.
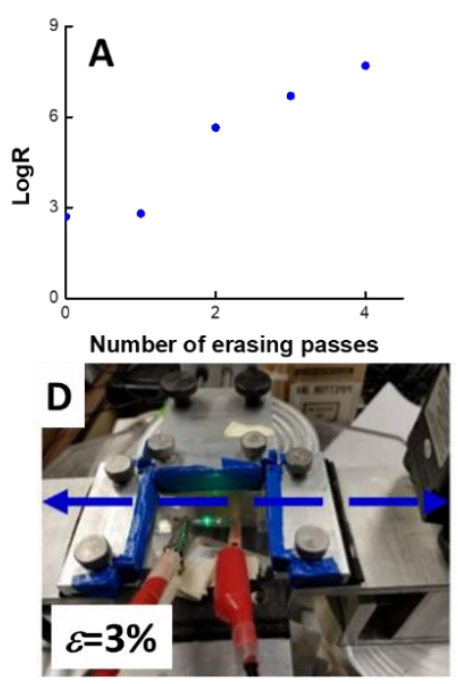
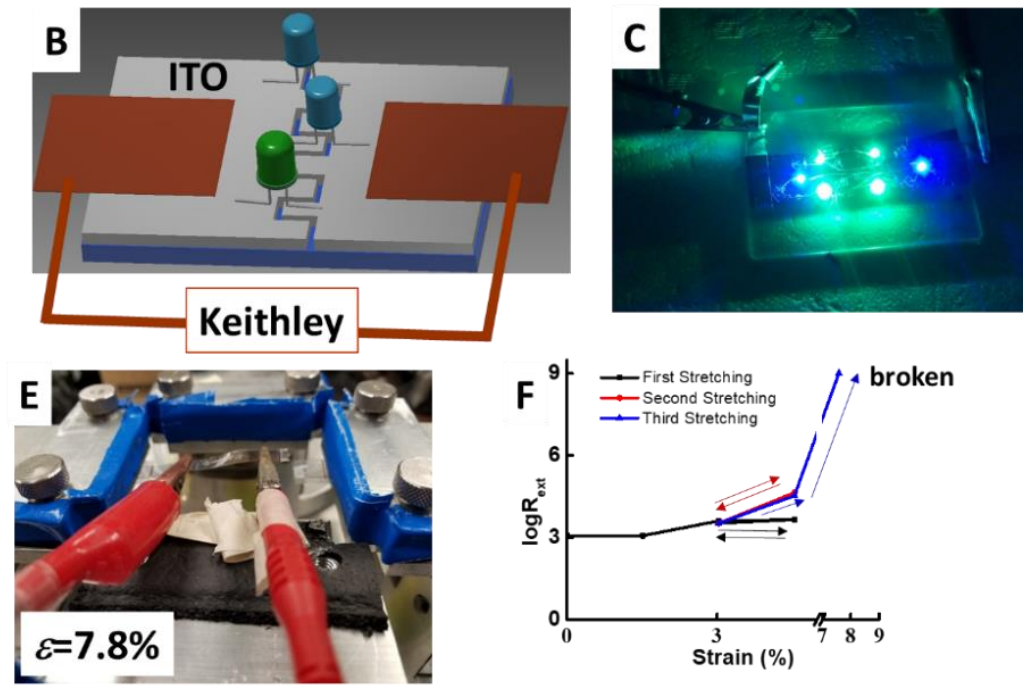

Figure 5. Testing of the LED assembly on the PLE fabricated ITO electrodes. (A) LogR-number of erasing passes dependence for the ITO electrodes. Here, R represents the electric resistance of the ITO electrode as a function of number of PLE erasing cycles. (B) Schematic of an LED assembly on ITO electrodes. (C) Four green and two blue LED assembled on an electrode fabricated across an ITO electrode that was fabricated using locomotion of a PLE probe impregnated with acidic $\mathrm{Fe}(\mathrm{III})$. The optical photographs of the LED devices assembled on flexible electrodes that were stretched with $\varepsilon=3 \%$ (D) and $7.8 \%(E)$. (F) LogRext- $\varepsilon$ dependence indicated that the electrical resistance was not affected significantly for $\varepsilon=3.3$ but the $R_{\text {ext }}$ increase exponentially at $\varepsilon>4.5 \%$. The device was damaged at $\varepsilon=7.5 \%$.

The performance of the devices fabricated in this study was limited by the shortrange extension failure due to material selection. With appropriate selection of base materials such as PDMS or PDMS-urethane composites, Rogers and Bao's groups recently demonstrated working devices that can be stretched larger strain $\varepsilon$ values up to or $>250 \% .{ }^{43,45,67}$ More extensive studies are currently underway for the 
fabrication of highly stretchable functional devices based on PLE for wearable pressure and motion sensing applications.

It is instructive to discuss the PLE in light of other lithography techniques widely used in the industry and academia. The surface selective patterning can be accomplished using many currently available tools including coated-AFM tips, focused ion beam (FIB), and electron beam lithography (EBL). For example, the selective removal of materials from a surface using AFM tips are demonstrated in the literature ${ }^{68}$. Importantly, AFM can remove materials from a surface through a mechanical process. However, this causes damage to the probe because of the physical contact between the tip and the surface, and the probe may need to be replaced if it is blunt due to damage. Similarly, FIB and electron lithography allows removal of materials and patterning at a high-resolution $(<100 \mathrm{~nm})$. However, the equipment and operating cost of these two instruments is high; many institutes and resource-limited countries cannot afford these expensive instruments. The PLE probe utilizes polymer and contains a liquid interface meniscus that reduces the friction during the locomotion of the probe. However, as demonstrated in this and in a previous manuscript, ${ }^{59}$ an electrochemical reaction facilitates the erasing process which can be many orders larger than the mechanical erasing of hard materials. Because chemical reaction performed at the microscale, a large number of materials are accessible for erasing at microscale. Further, multiple materials can be erased simultaneously, or a given material within a matrix of a composite made up of many species can also be erased. This opens new possibilities for fabricating new materials with spatial control at microscale level. Finally, the usage of a hydrogel 
ensures that the amount of ink enclosed within the polymeric matrix is several orders of magnitude higher than the dry weight of the polymer.

It is also important to consider the resolution and throughput rate of erasing using AFM, FIB, EBL, and that of PLE probes. The resolution of writing and erasing using AFM, FIB, and electron beam is $2-3$ orders better than the patterns made using the PLE probes. This is a direct consequence of the difference between the AFM and PLE probe size. ${ }^{59}$ Similarly, the electron and ion beams in FIB and EBL respectively allow much higher resolution erasing than that demonstrated in this study. Further studies may allow decrease in the erasing features using PLE (probably through sharper tip and through control of the experimental conditions). Additionally, the meniscus characteristics and experimental parameters such as humidity also influence the feature size of the patterns. Throughput rate (erasing and deposition rate) of the PLE based patterning is many orders of magnitude larger than those patterns composed using AFM, FIB, and EBL tools. This is because of the large differences in the probe/beam size. Finally, the erasing process demonstrated in this report is accomplished using an electrochemical reaction at much larger area which are practically impossible to accomplish using AFM-based probes with the same erasing speed. Overall, PLE, AFM, FIB, and EBL provide complementary tools that have potential applications in a wide field including microelectronics, biosensors, medical, and life-science.

\section{Conclusions}

We demonstrated the fabrication of functional devices based on interdigitated electrodes synthesized using probe-based etching of metallic coatings. Three 
different metallic coatings ( $\mathrm{Ag}, \mathrm{Cu}$, and ITO) on both hard and soft surfaces were erased and patterned using diffusion-based etchant delivery to the metal coating in contact mode between substrate and PLE. The translocation of PLE over a metallic coating allowed microscale erasing (etching) of metallic coating on demand in onestep process. Based on etchant concentration, PLE probe speed, and metal thickness, the microscale erasing features with minimum pattern size of $2.7 \mu \mathrm{m}$ was accomplished with etching rates of $\sim 8 \mu \mathrm{m}^{3} / \mathrm{s}$. Functional micro-photodetector and LED assemblies were fabricated on flexible and hard conductive interdigitated electrodes composed using PLE probes. Overall, the PLE allowed on-demand fast patterning of films of multiple metals with microscale features on both the soft and hard substrates for the fabrication of functional devices.

\section{Acknowledgements}

We would like to thank Prof. Kyle Plunkett for providing us a sample of P3HT, and Prof. P. Sivakumar for the use of his photometer. We also thank anonymous reviewers for their constructive comments that made the manuscript stronger.

\section{Associated content}

Scanning electron and optical micrographs of Si chip during photolithographic process. Detailed description of photolithography and Si anisotropic etching. SEM and EDS mapping/spectrum of PAAM pen editor loaded with etchants. SEM and EDS mapping of erased patterned silver using commercial etchant. Silver removal efficiency in atomic \% obtained using EDS. AFM characterization of PCBM and P3HT films. Absorption and emission spectrum of P3HT and composite P3HT:PCBM. Photograph of the mechanical stage used for mechanical tests. 


\section{Author Information}

\section{Corresponding Author}

*E-mail: pkohli@chem.siu.edu

\section{Author Contributions}

The manuscript was written through contributions of all authors. All authors have given approval to the final version of the manuscript.

\section{Funding Sources}

National Science Foundation: CHE 0748676, CHE 0959568, and DMR 1757954; and National Institutes of Health (GM 106364). CO and MB were supported through an NSF-REU award (DMR 1757954).

\section{Notes}

The authors declare no competing financial interests.

\section{References}

1. Salaita, K.; Wang, Y.; Mirkin, C. A., Applications of dip-pen nanolithography. Nature Nanotechnology 2007, 2, 145.

2. Piner, R. D.; Zhu, J.; Xu, F.; Hong, S.; Mirkin, C. A., "Dip-Pen" nanolithography. Science (New York, N.Y.) 1999, 283 (5402), 661-3.

3. Ginger, D. S.; Zhang, H.; Mirkin, C. A., The evolution of dip-pen nanolithography. Angewandte Chemie (International ed. in English) 2004, 43 (1), 30-45.

4. Braunschweig, A. B.; Huo, F.; Mirkin, C. A., Molecular printing. Nature chemistry 2009, 1 (5), 353-8.

5. Eichelsdoerfer, D. J.; Liao, X.; Cabezas, M. D.; Morris, W.; Radha, B.; Brown, K. A.; Giam, L. R.; Braunschweig, A. B.; Mirkin, C. A., Large-area molecular patterning with polymer pen lithography. Nature protocols 2013, 8 (12), 2548-60.

6. Huo, F.; Zheng, Z.; Zheng, G.; Giam, L. R.; Zhang, H.; Mirkin, C. A., Polymer pen lithography. Science (New York, N.Y.) 2008, 321 (5896), 1658-60.

7. Hedrick, J. L.; Brown, K. A.; Kluender, E. J.; Cabezas, M. D.; Chen, P. C.; Mirkin, C. A., Hard Transparent Arrays for Polymer Pen Lithography. ACS Nano 2016, 10 (3), 3144-8.

8. Xia, Y.; Whitesides, G. M., SOFT LITHOGRAPHY. Annual Review of Materials Science 1998, $28(1), 153-184$.

9. Kim, K.-H.; Moldovan, N.; Espinosa, H. D., A Nanofountain Probe with Sub-100 nm Molecular Writing Resolution. Small (Weinheim an der Bergstrasse, Germany) 2005, 1 (6), 632635. 
10. Loh, O. Y.; Ho, A. M.; Rim, J. E.; Kohli, P.; Patankar, N. A.; Espinosa, H. D., Electric fieldinduced direct delivery of proteins by a nanofountain probe. Proceedings of the National Academy of Sciences 2008, 105 (43), 16438.

11. Moldovan, N.; Keun-Ho, K.; Espinosa, H. D., Design and fabrication of a novel microfluidic nanoprobe. Journal of Microelectromechanical Systems 2006, 15 (1), 204-213.

12. Rogers, J. A.; Nuzzo, R. G., Recent progress in soft lithography. Materials Today 2005, 8 (2), 50-56.

13. Menard, E.; Meitl, M. A.; Sun, Y.; Park, J.-U.; Shir, D. J.-L.; Nam, Y.-S.; Jeon, S.; Rogers, J. A., Micro- and Nanopatterning Techniques for Organic Electronic and Optoelectronic Systems. Chemical Reviews 2007, 107 (4), 1117-1160.

14. Lenhert, S.; Sun, P.; Wang, Y.; Fuchs, H.; Mirkin, C. A., Massively Parallel Dip-Pen Nanolithography of Heterogeneous Supported Phospholipid Multilayer Patterns. Small (Weinheim an der Bergstrasse, Germany) 2007, 3 (1), 71-75.

15. Wang, W. M.; Stoltenberg, R. M.; Liu, S.; Bao, Z., Direct Patterning of Gold Nanoparticles Using Dip-Pen Nanolithography. ACS Nano 2008, 2 (10), 2135-2142.

16. Corletto, A.; Yu, L.; Shearer, C. J.; Gibson, C. T.; Shapter, J. G., Direct-Patterning SWCNTs Using Dip Pen Nanolithography for SWCNT/Silicon Solar Cells. Small (Weinheim an der Bergstrasse, Germany) 2018, 14 (16), e1800247.

17. Huang, L.; Braunschweig, A. B.; Shim, W.; Qin, L.; Lim, J. K.; Hurst, S. J.; Huo, F.; Xue, C.; Jang, J. W.; Mirkin, C. A., Matrix-assisted dip-pen nanolithography and polymer pen lithography. Small (Weinheim an der Bergstrasse, Germany) 2010, 6 (10), 1077-81.

18. Kumar, R.; Weigel, S.; Meyer, R.; Niemeyer, C. M.; Fuchs, H.; Hirtz, M., Multi-color polymer pen lithography for oligonucleotide arrays. Chemical Communications 2016, 52 (83), 12310-12313.

19. Kumar, R.; Bonicelli, A.; Sekula-Neuner, S.; Cato, A. C.; Hirtz, M.; Fuchs, H., Click-Chemistry Based Allergen Arrays Generated by Polymer Pen Lithography for Mast Cell Activation Studies. Small (Weinheim an der Bergstrasse, Germany) 2016, 12 (38), 5330-5338.

20. Xie, Z.; Chen, C.; Zhou, X.; Gao, T.; Liu, D.; Miao, Q.; Zheng, Z., Massively Parallel Patterning of Complex 2D and 3D Functional Polymer Brushes by Polymer Pen Lithography. ACS Applied Materials \& Interfaces 2014, 6 (15), 11955-11964.

21. Chung, S.-W.; Ginger, D. S.; Morales, M. W.; Zhang, Z.; Chandrasekhar, V.; Ratner, M. A.; Mirkin, C. A., Top-Down Meets Bottom-Up: Dip-Pen Nanolithography and DNA-Directed Assembly of Nanoscale Electrical Circuits. Small (Weinheim an der Bergstrasse, Germany) 2005, 1 (1), 64-69. 22. Lee, T.-W.; Jeon, S.; Maria, J.; Zaumseil, J.; Hsu, J. W. P.; Rogers, J. A., Soft-Contact Optical Lithography Using Transparent Elastomeric Stamps and Application to Nanopatterned Organic Light-Emitting Devices. Advanced Functional Materials 2005, 15 (9), 1435-1439.

23. O'Connell, C. D.; Higgins, M. J.; Moulton, S. E.; Wallace, G. G., Nano-bioelectronics via dippen nanolithography. Journal of Materials Chemistry C 2015, 3 (25), 6431-6444.

24. Mirkin, C. A.; Hong, S.; Demers, L., Dip-pen nanolithography: controlling surface architecture on the sub-100 nanometer length scale. Chemphyschem 2001, 2 (1), 37-39.

25. Hwang, K.; Shin, C.; Mingwu, R.; Lee, S.-H.; Kim, H.-m., Design of a nano-printer based on AFPN (Active Fountain Pen Nano-lithography) using switch control. Journal of Mechanical Science and Technology 2011, 25 (4), 977-985.

26. Zhang, H.; Elghanian, R.; Amro, N. A.; Disawal, S.; Eby, R., Dip Pen Nanolithography Stamp Tip. Nano Letters 2004, 4 (9), 1649-1655.

27. Liao, X.; Braunschweig, A. B.; Mirkin, C. A., "Force-feedback" leveling of massively parallel arrays in polymer pen lithography. Nano letters 2010, 10 (4), 1335-1340.

28. Jaeger, R. D.; Gleria, M., Inorganic polymers. Nova Science Publishers: New York, 2007. 
29. Eichelsdoerfer, D. J.; Brown, K. A.; Wang, M. X.; Mirkin, C. A., Role of Absorbed Solvent in Polymer Pen Lithography. The Journal of Physical Chemistry B 2013, 117 (50), 16363-16368.

30. Senesi, A. J.; Rozkiewicz, D. I.; Reinhoudt, D. N.; Mirkin, C. A., Agarose-Assisted Dip-Pen Nanolithography of Oligonucleotides and Proteins. ACS Nano 2009, 3 (8), 2394-2402.

31. Liu, G.; Zhou, Y.; Banga, R. S.; Boya, R.; Brown, K. A.; Chipre, A. J.; Nguyen, S. T.; Mirkin, C. A., The role of viscosity on polymer ink transport in dip-pen nanolithography. Chemical Science 2013, 4 (5), 2093-2099.

32. and, Y. X.; Whitesides, G. M., SOFT LITHOGRAPHY. Annual Review of Materials Science 1998, 28 (1), 153-184.

33. Schwartz, P. V., Molecular Transport from an Atomic Force Microscope Tip: A Comparative Study of Dip-Pen Nanolithography. Langmuir 2002, 18 (10), 4041-4046.

34. Urtizberea, A.; Hirtz, M.; Fuchs, H., Ink transport modelling in Dip-Pen Nanolithography and Polymer Pen Lithography. In Nanofabrication, 2016; Vol. 2.

35. Wang, X.; Wang, X.; Fernandez, R.; Ocola, L.; Yan, M.; La Rosa, A., Electric-Field-Assisted Dip-Pen Nanolithography on Poly(4-vinylpyridine) (P4VP) Thin Films. ACS Applied Materials \& Interfaces 2010, 2 (10), 2904-2909.

36. Amro, N. A.; Xu, S.; Liu, G.-Y., Patterning Surfaces Using Tip-Directed Displacement and Self-Assembly. Langmuir 2000, 16 (7), 3006-3009.

37. Liu, M.; Amro, N. A.; Liu, G.-Y., Nanografting for Surface Physical Chemistry. Annual Review of Physical Chemistry 2008, 59 (1), 367-386.

38. Li, Y.; Maynor, B. W.; Liu, J., Electrochemical AFM “Dip-Pen” Nanolithography. Journal of the American Chemical Society 2001, 123 (9), 2105-2106.

39. Tinazli, A.; Piehler, J.; Beuttler, M.; Guckenberger, R.; Tampé, R., Native protein nanolithography that can write, read and erase. Nature Nanotechnology 2007, 2 (4), 220-225.

40. Rajasekaran, P. R.; Zhou, C.; Dasari, M.; Voss, K.-O.; Trautmann, C.; Kohli, P., Polymeric lithography editor: Editing lithographic errors with nanoporous polymeric probes. Science Advances 2017, 3 (6).

41. Dahl-Young Khang, H. J., Young Huang, John A. Rogers, A Stretchable Form of SingleCrystal Silicon for High-Performance Electronics on Rubber Substrates. Science (New York, N.Y.) 2006, 311, 5 .

42. Kim, D.-H.; Ahn, J.-H.; Choi, W. M.; Kim, H.-S.; Kim, T.-H.; Song, J.; Huang, Y. Y.; Liu, Z.; Lu, C.; Rogers, J. A., Stretchable and Foldable Silicon Integrated Circuits. Science (New York, N.Y.) 2008, 320 (5875), 507-511.

43. Kim, D.-H.; Ghaffari, R.; Lu, N.; Rogers, J. A., Flexible and Stretchable Electronics for Biointegrated Devices. Annual Review of Biomedical Engineering 2012, 14 (1), 113-128.

44. Kunnavakkam, M. V.; Houlihan, F. M.; Schlax, M.; Liddle, J. A.; Kolodner, P.; Nalamasu, O.; Rogers, J. A., Low-cost, low-loss microlens arrays fabricated by soft-lithography replication process. Applied Physics Letters 2003, 82 (8), 1152-1154.

45. Rogers, J. A.; Someya, T.; Huang, Y., Materials and Mechanics for Stretchable Electronics. Science (New York, N.Y.) 2010, 327 (5973), 1603-1607.

46. Xu, S.; Yan, Z.; Jang, K.-I.; Huang, W.; Fu, H.; Kim, J.; Wei, Z.; Flavin, M.; McCracken, J.; Wang, R.; Badea, A.; Liu, Y.; Xiao, D.; Zhou, G.; Lee, J.; Chung, H. U.; Cheng, H.; Ren, W.; Banks, A.; Li, X.; Paik, U.; Nuzzo, R. G.; Huang, Y.; Zhang, Y.; Rogers, J. A., Assembly of micro/nanomaterials into complex, three-dimensional architectures by compressive buckling. Science (New York, N.Y.) 2015, 347 (6218), 154-159.

47. Yugang Sun, W. M. C., Hanqing Jiang, Yonggang Y. Huang and John A. Rogers, Controlled buckling of semiconductor nanoribbons for stretchable electronics. Nature Nanotechnology 2006, 1,7 . 
48. Hammock, M. L.; Chortos, A.; Tee, B. C. K.; Tok, J. B. H.; Bao, Z., 25th Anniversary Article: The Evolution of Electronic Skin (E-Skin): A Brief History, Design Considerations, and Recent Progress. Advanced Materials 2013, 25 (42), 5997-6038.

49. Sokolov, A. N.; Tee, B. C. K.; Bettinger, C. J.; Tok, J. B. H.; Bao, Z., Chemical and Engineering Approaches To Enable Organic Field-Effect Transistors for Electronic Skin Applications. Accounts of Chemical Research 2012, 45 (3), 361-371.

50. Finne, R. M.; Klein, D. L., A Water-Amine-Complexing Agent System for Etching Silicon. Journal of The Electrochemical Society 1967, 114 (9), 965-970.

51. Tse, J. R.; Engler, A. J., Preparation of hydrogel substrates with tunable mechanical properties. Current protocols in cell biology 2010, Chapter 10, Unit 10.16.

52. Pal, P.; Sato, K., A comprehensive review on convex and concave corners in silicon bulk micromachining based on anisotropic wet chemical etching. Micro and Nano Systems Letters 2015, $3(1), 6$.

53. Choi, T.-S.; Hess, D. W., Chemical Etching and Patterning of Copper, Silver, and Gold Films at Low Temperatures. ECS Journal of Solid State Science and Technology 2015, 4 (1), N3084-N3093. 54. Love, J. C.; Paul, K. E.; Whitesides, G. M., Fabrication of Nanometer-Scale Features by Controlled Isotropic Wet Chemical Etching. Advanced Materials 2001, 13 (8), 604-607.

55. Cui, A.; Liu, Z.; Dong, H.; Wang, Y.; Zhen, Y.; Li, W.; Li, J.; Gu, C.; Hu, W., Single Grain Boundary Break Junction for Suspended Nanogap Electrodes with Gapwidth Down to 1-2 nm by Focused Ion Beam Milling. Advanced Materials 2015, 27 (19), 3002-3006.

56. Saubestre, E. B., Copper Etching in Ferric Chloride. Industrial \& Engineering Chemistry 1959, 51 (3), 288-290.

57. Bryce, C.; Berk, D., Kinetics of the dissolution of copper in iron(III) chloride solutions. Industrial \& Engineering Chemistry Research 1995, 34 (4), 1412-1418.

58. Burrows, W. H.; Lewis, C. T.; Saëre, D. E.; Brooks, R. E., Kinetics of the Copper-Ferric Chloride Reaction and the Effects of Certain Inhibitors. Industrial \& Engineering Chemistry Process Design and Development 1964, 3 (2), 149-159.

59. Rajasekaran, P. R.; Zhou, C.; Dasari, M.; Voss, K.-O.; Trautmann, C.; Kohli, P., Polymeric lithography editor: Editing lithographic errors with nanoporous polymeric probes. Science Advances 2017, 3 (6), e1602071.

60. Rozhok, S.; Piner, R.; Mirkin, C. A., Dip-Pen Nanolithography: What Controls Ink Transport? The Journal of Physical Chemistry B 2003, 107 (3), 751-757.

61. Chirvase, D.; Chiguvare, Z.; Knipper, M.; Parisi, J.; Dyakonov, V.; Hummelen, J. C., Temperature dependent characteristics of poly(3 hexylthiophene)-fullerene based heterojunction organic solar cells. Journal of Applied Physics 2003, 93 (6), 3376-3383.

62. Kautsky, H., Quenching of luminescence by oxygen. Transactions of the Faraday Society 1939, 35 (0), 216-219.

63. Hintz, H.; Egelhaaf, H. J.; Lüer, L.; Hauch, J.; Peisert, H.; Chassé, T., Photodegradation of P3HT-A Systematic Study of Environmental Factors. Chemistry of Materials 2011, 23 (2), 145-154.

64. Reese, M. O.; Nardes, A. M.; Rupert, B. L.; Larsen, R. E.; Olson, D. C.; Lloyd, M. T.; Shaheen, S. E.; Ginley, D. S.; Rumbles, G.; Kopidakis, N., Photoinduced Degradation of Polymer and PolymerFullerene Active Layers: Experiment and Theory. Advanced Functional Materials 2010, 20 (20), 3476-3483.

65. Dasari, M.; Rajasekaran, P. R.; lyer, R.; Kohli, P., Calligraphic solar cells: acknowledging paper and pencil. Journal of Materials Research 2016, 31 (17), 2578-2589.

66. van den Meerakker, J. E. A. M.; Baarslag, P. C.; Scholten, M., On the Mechanism of ITO Etching in Halogen Acids: The Influence of Oxidizing Agents. Journal of The Electrochemical Society 1995, 142 (7), 2321-2325. 
67. Son, D.; Kang, J.; Vardoulis, O.; Kim, Y.; Matsuhisa, N.; Oh, J. Y.; To, J. W. F.; Mun, J.; Katsumata, T.; Liu, Y.; McGuire, A. F.; Krason, M.; Molina-Lopez, F.; Ham, J.; Kraft, U.; Lee, Y.; Yun, Y.; Tok, J. B. H.; Bao, Z., An integrated self-healable electronic skin system fabricated via dynamic reconstruction of a nanostructured conducting network. Nature Nanotechnology 2018, 13 (11), 1057-1065.

68. Jang, J.-W.; Maspoch, D.; Fujigaya, T.; Mirkin, C. A., A “Molecular Eraser” for Dip-Pen Nanolithography. Small 2007, 3 (4), 600-605. 